\title{
Collective Community Empowerment Flood Coping Strategy and Sustainable Livelihood Security of Riverine Community of Jowhar District in Somalia.
}

\author{
SAMAN ABDI HAJJI *, Dr. NAOMI NDUTA NJOROGE (Ph.D.) ** \\ ${ }^{*}$ MA (Development Studies) Student, Program officer, UN- Food and Agriculture Organization, Department of Social and \\ Development Studies, School of Social Science, Mount Kenya University, Kenya \\ ${ }^{* *}$ Monitoring and Evaluation Expert, Department of Social and Development Studies, School of Social Science, Mount Kenya \\ University, Kenya:
}

DOI: 10.29322/IJSRP.11.12.2021.p12066

http://dx.doi.org/10.29322/IJSRP.11.12.2021.p12066

\begin{abstract}
In Somalia, the severity and frequency of flooding has increased dramatically over the last few decades, posing a serious threat to the livelihoods of the local population. In the recent past, the Somali government and other humanitarian organizations have worked closely with communities that have been threatened by floods. The goal of this article is to look at the impact of collective community empowerment as a flood coping method on riverine community livelihood security in Somalia's Jowhar District. The paper is an excerpt from an empirical study on the impact of flood coping measures on the riverine community's long-term livelihood security in Somalia's Jowhar district. The 884 households residing along the Shabelle riverine in Jowhar District were studied using a mixed method approach. The 275 households from which the family heads were surveyed were sampled using a simple random sampling method. The key informants, which included community leaders, government officials, and humanitarian organization management professionals, were purposefully chosen to provide qualitative information via an in-depth interview guide. Thematical analysis of qualitative data obtained from key informants was combined with descriptive statistics using SPPS software to analyze quantitative data. The study found that the scale of community collective empowerment in dealing with flood results was critical to the long-term viability of riverine community home security. According to the findings of the study, decision-makers should empower the community collectively by involving them in making decisions that are likely to change their flood risk perception, as well as raising awareness about practical land use measures to reduce flood frequency and increase resilience in coping with flood consequences.
\end{abstract}

Key words: Flood coping strategy, Community collective empowerment, sustainable livelihood security.

\section{INTRODUCTION}

\section{Background of the Study}

The question of long-term livelihood security has been a worry not only in Somalia, but also in other parts of the world. Flood damage is widespread, accounting for 90 percent of all-natural catastrophe damages in the United States (Anyamba, 2019). According to the National Weather Service in the United States, floods render around 95 percent of people unable to engage in necessary productive activities, increasing family vulnerability. Reduced income-generating opportunities reduce future generations' chances of gaining better access to resources for long-term livelihood security. According to studies, such situations can be avoided by employing a variety of tactics. This article looks into the impact of community collective empowerment on the riverine community's long-term livelihood stability.

Somalia, as a developing country, has experienced its fair share of natural calamities in recent years. Major areas of the country have seen their resources decimated and population displaced regularly in recent years as a result of such unmitigated calamities, and Jowhar district has been among victims of flooding (Nicholson, 2017). Asumadu-Sarkodie, (2015) notes the current surge in flooding events in Somalia which has posed a huge threat to their livelihood security of the community therein.

Meanwhile, the Somali government and non-governmental organizations have worked closely to empower flood-prone communities. Nonetheless, despite the introduction of flood coping methods, the communities' livelihoods have remained subject to ever-increasing flood losses. More information from the literature reveals a variety of flood coping tactics that were used before, during, and after the floods to help flood victims maintain their livelihood stability. Despite this discovery, little is known about the relationship between community collective empowerment and long-term livelihood stability in the Riverine community, particularly in Somaliland's Jowhar District.

It is therefore critical to develop a link between community collective empowerment and the long-term sustainability of Somalia's riverine community's livelihood. This will aid in the incorporation of the findings into local initiatives aimed at enhancing and sustaining the livelihood security of populations living in disaster-prone areas. 


\section{LITERATURE REVIEW}

Natural disasters are unavoidable, and no amount of research or preparation, no matter how thorough, will be enough to prevent them. However, efforts can always be taken and successful in reducing their impact on the livelihood security of communities. In the case of a flood, empowering the communities who are most likely to be affected is critical to reducing flood risks and damages. According to a UNDP assessment from 2004, the Nyando flood plain in Kenya has continued to undergo exceptionally heavy rains and enormous catastrophic floods, citing it as one of the greatest calamities harming locals' lives (Ahadzie, and Proverbs, 2011).

The Consortium for research and sustainable development projects helped flood victims by providing early warning systems, humanitarian aid, and capacity building in entrepreneurship, climate wise agriculture, adaptive and alternative livelihoods. In support of this report, a study by Samuel Yaw Danso and Isaac Yeboah Addo (2016) resolved that capacity building has an influence on knowledge, skills, and attitude transformation, allowing them to break free from poverty cycles by engaging in long-term income-generating activities.

Community empowerment is a critical component of reducing health inequalities and achieving a higher quality of life. Aldrich and Benson (2008) conducted practical research in Juba that demonstrated how community disaster planning can significantly reduce the scale of any disaster. Similarly, Rajeev (2014) stated that community empowerment is important in capacity building because it allows members of the community to actively make decisions about disaster risk management goals and strategies while also contributing some, if not all, of the resources needed and monitoring their performance. Effective coping mechanisms would be applied if the flood mitigation plans were owned by the likely victims, reducing the disaster's impact. As a method for dealing with and managing disasters, the various community categories should be empowered differently for all rounded flood mitigation measures.

The community's involvement in disaster phases is governed by a number of criteria. According to Rozita and Chamhuri (2017), socio-demographic and health impact factors have a significant impact on the characteristics of societal empowerment. The identification of such parameters' effects in flood-prone communities would provide valuable insight into the link between flooding threats and community livelihood security. Furthermore, it aids in the creation and implementation of empowerment initiatives that improve the survival rates of the impacted households.

According to Hall, (2014), communities' sensitivity to the effects of future flooding can be considerably minimized. The author contends that by empowering communities to advance floodprevention procedures, they can achieve self-sustainability and a non-government coping technique for disaster mitigation and preparedness that can be replicated. This can be achieved by providing households with higher levels of security from such disasters, training village volunteers in disaster concepts and strategies, establishing a local disaster community, and money mobilization for self-sufficiency for the people concerned, according to the new knowledge gained from this study. As a result, the reviewed literature designates a strong link between catastrophe victims' socio-economic strength and their level of empowerment in several areas for sustaining their livelihoods.

\section{RESEARCH METHODOLOGY}

The goal of the study done was to generate quantitative information on developing resilience among the riverine population in Jowhar District, Somalia, using a cross-sectional descriptive survey to enable collection of information rich data at a certain point in time. The quantity, amount, and range were expressed using quantitative data. Furthermore, qualitative data gathered from the key informants via an interview guide was used to develop a thorough understanding of riverine community collective empowerment and long-term livelihood stability. The respondents had substantially more time during the interview to share their flood coping plans, feelings, and constraints on their livelihood security. The study looked at all 884 houses in Bada'as village who are exposed to flood disasters. Yamane's formula (1967) was used to determine a representative group of 275 households, which were accurately sampled using a systematic random sampling technique. A village chief, a government official, and two representatives from humanitarian organizations on the ground then were purposefully chosen as the key to provide qualitative data for more conclusive and validated data.

\section{RESEARCH FINDINGS}

\section{Questionnaire Return Rate}

The 275-survey questionnaire sent to the household heads yielded a total of 200 viable questionnaires. According to Mugenda \& Mugenda (2003), a response rate of $70 \%$ is adequate, thus the response rate was 73 percent, which was regarded appropriate for analysis and conclusion. The questionnaire return rate is shown in Table 4.1.

Table 4.1 Questionnaire Return Rate

\begin{tabular}{lll}
\hline Response & Frequency & Percent \\
\hline Filled questionnaire & 200 & 73 \\
$\begin{array}{l}\text { Unfilled } \\
\text { questionnaires }\end{array}$ & 75 & 27 \\
\hline Total & $\mathbf{2 5 0}$ & $\mathbf{1 0 0}$ \\
\hline
\end{tabular}

\section{Community Collective Empowerment and sustainable Livelihood Security}

The Community in Jowhar District were collectively empowered towards building resilience on coping with floods consequences. On this variable, the respondents were asked to indicate their level of agreement or disagreement in a Likert scale of 1-5 where; 1=Strongly Disagree (SD), 2=Disagree (D), 3=Neutral (N), 4=Agree (A), and 5=strongly agree (SA).

The first line item stated that the community participates in evaluations of their vulnerabilities and flood risks, although some respondents $71(35.5 \%)$ never supported this statement, 103(53\%) of the respondents confirmed their involvement in the said excise. $26(13 \%)$ had no commitment on this assertion, either they lacked valid information or they had not made up their minds. The line 
item had a mean of 3.31 and a standard deviation of 1.331 , which was higher than the overall composite means of 2.98 and SD of 1.349 in favor of the line statement.

The second line item indicated that process for developing flood response plans include input from various stakeholders and partners including community representatives. However, $51(25.5 \%)$ respondents disagreed with the statement at different magnitude. Among the respondents, 111(54\%) were in support of this assertion. The neutral response was represented by $31(15.5 \%)$ respondents which was not by chance or random. The line item had a mean of 3.56 and a standard deviation of 1.308 , which was higher than the overall composite means of 2.98 and SD of 1.349. This means that the community's flood response plans are developed with input from a variety of stakeholders and partners who represent all of the families affected by the river's flooding.

The third line item indicated that CBOs are formed for emergency preparedness, trainings and supports from relevant partners like NGOs however there are some respondents who disagreed with the statement $50(25.0 \%)$. Neutral were $41(20.5 \%)$ meaning that they were not decided or were not committed to the flood response measures. However, those who agreed were 109 (55\%), thumb stamping contribution of CBOs in flood measures. The line item had a mean score of 3.52 and a SD of 1.232, higher score than the overall composite means of 2.98 and 1.349. This infers creation of CBOs for emergency preparedness, trainings and supports from relevant partners like NGOs make it easy for the community to participate fully in the flood control measures.

The fourth line item indicated that there are basic equipment and requirements put in place as coping strategies occurrence of floods although there are those respondents $64(31 \%)$ who stood against this statement. Neutral cases were $38(19.0 \%)$ meaning that they were not decided or were non-committal to the study objective. However, those who were in support of the statement $100(50.0 \%)$ were the majority. The line item had a mean score of 3.52 and a SD of 1.232 higher score than the overall composite means of 2.98 and 1.349. This implies that there are basic equipment and requirements put in place as coping strategies when there are occurrences of floods in the community.

The fifth line item indicated that financial resources are allocated for identified essential flood response supplies and equipment such as shelter, food and water. Majority of the respondents 78 $(39 \%)$ supported this variable indicator although there are those respondents who disagreed with the statement 90(45\%). Neutral responses were $32(16.0 \%)$ indicating non commitment or minimal information on this study objective. The line item had a mean score of 3.04 and a SD of 1.372 higher score than the overall composite means of 2.98 and SD of 1.349. This implies that financial resources are allocated for identified essential flood response supplies and equipment such as shelter, food, water for community to make good use on them.

The sixth line item indicated that emergency preparedness and response awareness activities are integrated in school curricula for knowledge development although there are those respondents who disagreed with the statement 54(27\%). Neutral responses were $29(14.5 \%)$ inferring non commitment or lack of information on the study variables. However, those who agreed with the statement were the majority $117(58.5 \%)$. The line item had a mean score of 3.49 and SD of 1.284 higher score than the overall composite mean of 2.98 and 1.349. This confirms integration of the emergency preparedness and response awareness activities in school curricula for knowledge development.

The seventh line item indicated risks and vulnerability assessments are identified in the community; a statement supported by the majority of the respondents $93.5(46.5 \%)$ with $64(43 \%)$ against the statement. Neutral cases were $43(21.5 \%)$ meaning that they were not decided. The line item had a mean score of 3.68 and a SD of 1.142 higher score than the overall composite means of 2.98 and 1.349. This suggests that risks and vulnerability assessments are identified in the community making it easy for families to be able to assess the risks identified for necessary assessments.

The eighth line item indicated as part of preparedness efforts, training mechanisms for emergency response are put in place although there are those respondents who never supported the statement 73(36.5\%). Neutral responses were 44(22\%) indicating non commitment or lack of necessary on the study objective. However, those who were in agreement were $83(41.5 \%)$. The line item had a mean score of 3.16 and a SD of 1.249 higher score than the overall composite mean of 2.98 and 1.349 . This indicates that as part of preparedness efforts, training mechanisms for emergency the community should be well informed their roles when it comes to preparedness of the floods.

The opinion of the influence of the flood coping strategies on the livelihood security of the riverine community by the government, community leaders and the humanitarian representatives were captured through the interview. On the influence of the community collective empowerment flood coping strategy on the community livelihood security, one of the key informants stated that:

"There are plans for addressing the issue offloods
occurrence and the aftermath once and for all.
Although this one can only be made a reality a
bigger number of the members in the community
are involved in the decision and implementation
process"

In support of this sentiment, another official said that 'Occasionally, there are open Barrazas within the government structures where community members are educated on the environmental issues likely to impact on their livelihood and how to effectively cope with the floods consequences."

However, another official had a concern,

'We have always had some challenges in the attendance of the local training set for the community by the humanitarian bodies despite being free and accessible. There are very few community members who volunteer, yet it is for the benefits of their safe survival'.

Concerning the household income sources, one of the community leaders did a comment on Job creation and said that: 
"most of the Young men were not employed and wholly relied on the informal jobs from the families and that employment opportunities have become so minimal since the flooding started affecting the area."

The findings of this study are backed up by findings from other academic studies. Community empowerment, according to Rajeev (2014), is an integral feature of capacity building because it allows members of the community to actively make decisions about disaster risk management goals and strategies while also contributing required inputs and monitoring their performance. Once the flood mitigation plans are owned by the prospective victims, effective coping procedures can be implemented, reducing the impact on livelihoods. Similarly, Njome, Chuyong, and Wit (2010) found that involving community members who are vulnerable to disasters encourages them to turn their newfound knowledge into coping mechanisms targeted at preventing, mitigating, coping with, or resisting similar or different disasters in the future.

This finding suggests that flood-prone communities were included in assessments of their vulnerabilities and flood risks, and that disaster preparedness and response awareness activities are integrated into school curriculum for knowledge development at all levels. From these findings, it can be deduced that floods have an impact on the stability of the respondents' buildings, which is directly linked to long-term livelihood insecurity. It was discovered that for chronically vulnerable populations, community-focused interventions may be required in order for provisioning activities to be taken over by the community on a long-term basis.

The study's analysis of community collective empowerment found that the community was only partially involved in the evaluations of its flood vulnerabilities and risks. When community representatives are given the opportunity to engage in decisionmaking that affects their livelihood, the empowerment will be endorsed by the entire community for sustainable livelihood security. Similarly, training community members in emergency preparedness, response awareness, and flood mitigation is linked to sustainable livelihood security. With an overall composite mean of 3.56 and a standard deviation of 1.308, collective community empowerment flood coping strategy was observed to promote sustainable livelihood security. This suggests that empowering community members improves their ability to cope with flooding, which in turn helps them maintain their livelihood security.

The study concluded that the riverine community households' sustainability is depending on individual income sources, food availability, social facilities, and available job opportunities for locals. The riverine community's collective community empowerment was discovered to have been a major impact on the riverine households' sustainable livelihood security. Furthermore, involving community leaders in decision-making about community flood coping strategies encouraged total ownership and practice of the studied strategies, allowing for smooth flood response. Additionally, having access to important information and knowledge about flood occurrences facilitates early emergency preparedness and the implementation of security measures to avoid unforeseen risks. As a result, it was established that a well-organized and collectively empowered community is better able to deal with calamities, particularly floods, and maintain their livelihood security.

It was clear, and thus a conclusion, that improving flood victims' community empowerment strategies improves their ability to cope with flood aftermaths. As a result, the study concluded that the government and humanitarian organizations on the ground should consider investing financial resources to establish proper surveillance, early warning systems, and widespread flood reporting. Similarly, flood impacts information from disaster monitors should be shared with community leaders timely.

\section{RECOMMENDATIONS}

\section{Recommendation of the Study}

The riverine community's livelihood security includes, consistent revenue streams, functional social amenities, and stable job opportunities among other things. The findings from this paper suggests that, in order to assure the long-term sustainability of the communities' livelihood security, local communities should be actively involved in decision-making that is likely to influence their perception of flood risk and awareness of sensible land use and related flood mitigation measures.

\section{REFERENCES}

1) Abraham, B. K. (2018). Influence of project monitoring and evaluation on the performance of youth funded projects: A case of Moiben Subcounty Uasin Gishu County, Kenya . Retrieved from http://41.204.161.209/handle/11295/104158

2) Akello, E., \& Moronge, M. (2019). Influence of monitoring and evaluation on completion of government funded agricultural projects in arid and semi -arid areas of Kenya: A case of Marsabit County. The Strategic Journal of Business \& Change Management, 6(2), 1329 1344.

3) (Nicholson, 2017). Resilience and Adaptation Strategies of Rural Livelihoods in Tonle Sap area. Master's Thesis. Cambodia: Department of Geography, University of Helsinki.

4) Ahadzie, D.K., and Proverbs, D.G., 2011. Emerging issues in the management of floods in Ghana. International Journal of Safety and Security Engineering, 1 (2), 182-192

5) Aldrich N. Benson W. F. (2008). Disaster preparedness and the chronic disease needs of vulnerable older adults. Preventing chronic disease, Vol. 5 (1), A27.

6) Anyamba, (2019) Evaluating the effect of flood damage-reducing measures: A case study of the unembanked area of Rotterdam, the Netherlands. Regional Environmental Change, 2014; 14(3):895-908.

7) Asumadu-Sarkodie, (2015) Flood proneness and coping strategies: the experiences of two villages in Bangladesh Shitangsu Kumar

8) Hall R. (2014). Adaptive Governance Policy for Societal Resilience and Community Empowerment, Vol. 11 (12), 949-959,

9) Mugenda, O.M., \& Mugenda, A.G. (2003). Research Methods: Quantitative \& Qualitative Approaches, Nairobi: Act Press. 
10) Njome M, Chuyong G, de Wit M. Volcanic risk perception in rural communities along the slopes of Mt. Cameroon, west Central Africa. Journal of African Earth Sciences. 2010; 58:608

11) Rajeev (2014), Rajeev M. M. Sustainability and Community Empowerment in Disaster Management, 2 (6), 207-212, 2014

12) Rozita Hod1, Chamhuri Siwar2 (2017), Mohd Raihan Taha2 1 Community Empowerment and the Associated Factors among the 2014 Flood Victims in Pahang Universal Journal of Public Health 5(3): 119126, 2017 http://www.hrpub.org DOI: 10.

13) Samuel Yaw Danso \&Isaac Yeboah Addo (2016) copping strategies of households affected by flooding: A case study of Sekondi-Takoradi Metropolis in GhanaPages 539-545 | received 26 Aug 2015, Accepted 04 Apr 2016, Published onli

\section{AUTHORS}

First Author-MA (Development Studies) Student, Program officer, UN- Food and Agriculture Organization, Department of Social and Development Studies, School of Social Science, Mount Kenya University, Kenya: email; Samanabdi1@ gmail.com

Second Author - Dr. Naomi Nduta Njoroge (Ph.D.), Monitoring and Evaluation Expert, Department of Social and Development Studies, School of Social Science, Mount Kenya University, Kenya: email; Ndutanjoroge600@ gmail.com 